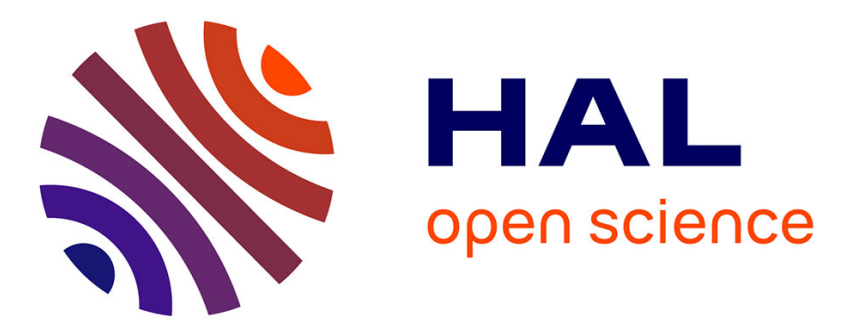

\title{
Influence of hard segment content and nature on polyurethane/multiwalled carbon nanotube composites
}

Borja Fernández-d'Arlas, Umar Khan, Lorena Rueda, Jonathan N. Coleman, Iñaki Mondragon, Maria A. Corcuera, Arantxa Eceiza

\section{- To cite this version:}

Borja Fernández-d'Arlas, Umar Khan, Lorena Rueda, Jonathan N. Coleman, Iñaki Mondragon, et al.. Influence of hard segment content and nature on polyurethane/multiwalled carbon nanotube composites. Composites Science and Technology, 2011, 71 (8), pp.1030. 10.1016/j.compscitech.2011.02.006 . hal-00753178

\section{HAL Id: hal-00753178 \\ https://hal.science/hal-00753178}

Submitted on 18 Nov 2012

HAL is a multi-disciplinary open access archive for the deposit and dissemination of scientific research documents, whether they are published or not. The documents may come from teaching and research institutions in France or abroad, or from public or private research centers.
L'archive ouverte pluridisciplinaire HAL, est destinée au dépôt et à la diffusion de documents scientifiques de niveau recherche, publiés ou non, émanant des établissements d'enseignement et de recherche français ou étrangers, des laboratoires publics ou privés. 


\section{Accepted Manuscript}

Influence of hard segment content and nature on polyurethane/multiwalled carbon nanotube composites

Borja Fernández-d'Arlas, Umar Khan, Lorena Rueda, Jonathan N. Coleman, Iñaki Mondragon, Maria A. Corcuera, Arantxa Eceiza

PII: S0266-3538(11)00073-X

DOI: 10.1016/j.compscitech.2011.02.006

Reference: CSTE 4931

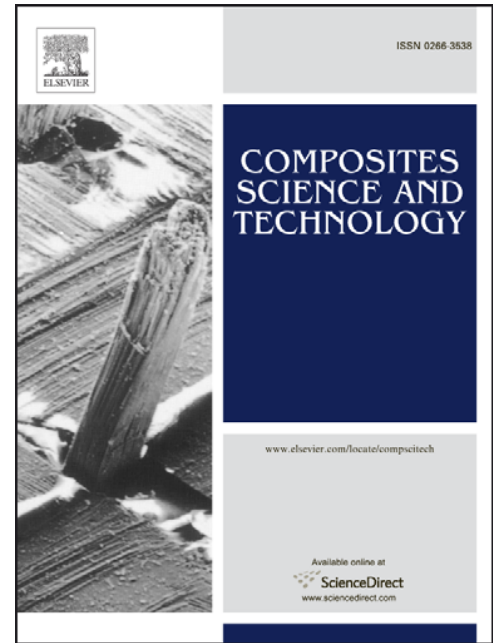

To appear in:

Composites Science and Technology

Received Date:

11 November 2010

Revised Date:

13 February 2011

Accepted Date:

14 February 2011

Please cite this article as: Fernández-d'Arlas, B., Khan, U., Rueda, L., Coleman, J.N., Mondragon, I., Corcuera, M.A., Eceiza, A., Influence of hard segment content and nature on polyurethane/multiwalled carbon nanotube composites, Composites Science and Technology (2011), doi: 10.1016/j.compscitech.2011.02.006

This is a PDF file of an unedited manuscript that has been accepted for publication. As a service to our customers we are providing this early version of the manuscript. The manuscript will undergo copyediting, typesetting, and review of the resulting proof before it is published in its final form. Please note that during the production process errors may be discovered which could affect the content, and all legal disclaimers that apply to the journal pertain. 


\section{Influence of hard segment content and nature on}

\section{polyurethane/multiwalled carbon nanotube composites}

Borja Fernández-d'Arlas ${ }^{1}$, Umar Khan ${ }^{2}$, Lorena Rueda ${ }^{1}$, Jonathan N. Coleman ${ }^{2}$, Iñaki Mondragon $^{1}$, Maria A. Corcuera ${ }^{1}$, Arantxa Eceiza $^{1 *}$

1 “Materials+Technologies" Group, Polytechnic School. University of the Basque Country, Pza. Europa 1, 20018 Donostia-San Sebastián (Spain)

2 “Chemical-Physics of Low-Dimension Nanostructures” Group, School of Physics. Trinity College of Dublin, Dublin 2 (Ireland)

* Corresponding author tel.: (0034)-943-017185

e-mail: arantxa.eceiza@ehu.es 


\begin{abstract}
Knowledge of how polyurethanes, PU, complexity affects their derived multiwalled carbon nanotube, MWCNT, composites could shed important clues for preparing future tailored PU/MWCNT elastic, strong and electrically conductive composites. In this regard, hard segment content and nature, along with MWCNT functionalisation, are believed to have great influence on both nanoscale PU/MWCNT self assembling mechanisms and on final composites properties. In this work the effect of PU hard segment content into composites was analysed. According to the results, a preferential interaction of nanotubes with polyurethanes hard segments can be assumed although nanotubes introduction hindered both soft and hard segments crystallisation. In all cases carbon nanotubes percolative network formation seemed to be crucial for obtaining significant reinforcement, being observed at this stage, a reduction of ductility, phenomena which is related to an increase on hard domains interconnections by MWCNT. The hard to soft segment ratio into PU plays a crucial role on determining the stress transfer to MWCNT. In addition, PU hard domains nature has important effect on nanotubes reinforcing character, this fact being related to the different PU intrinsic morphologies as well as different PU-MWCNT interactions.
\end{abstract}

Keywords:
A. Carbon nanotubes

A. Polymer-matrix composites (PMCs)

B. Mechanical properties

B. Fracture

B. Interfacial strength 


\section{Introduction}

The concept of creating both structural and functional multi-nanophase composites with improved performance is currently under development in a wide variety of metallic, ceramic and polymeric matrices, although the emphasis to date has been on polymeric systems [1-3]. By introducing carbon nanotubes (CNT) into a polymer matrix, many properties can be improved at once, including mechanical [4,5], thermo-mechanical [6], electrical [7,8], thermal $[9,10]$, chemical [11] and optical properties [12].

Polyurethane (PU) is among the most versatile materials today [13-15] and can be tailored according to the desired application requirements choosing carefully the reactants, their ratio and their synthesis procedure [16]. Different combinations of strength, ductility, biodegradability or hardness can be achieved with the proper formulation and preparation. Nevertheless there are still some properties such as thermal stability, electrical and thermal conductivity, stiffness or stress recovery, which could be improved with the addition of CNT. Combination of polyurethane elastomers with CNT might lead to new functional materials with combined properties.

Some researches have focused more on the applicability of PU/CNT composites to different fields such as biomedicine [17-19], adding benefit of the unique properties of CNT, while some others have focused more on the materials science point of view [20]. While in some works the research was focused on understanding the effects of the addition of CNT to a polyurethane matrix through melt blending [21] or solvent mixing [22-24], in some others it has been tried to benefit from the polyurethanes chemistry to prepare grafted nanotubes hybrids which were further polymerised in-situ with the aim of creating CNT cross-linked networks 
[25-30], or to functionalise the nanotubes and then solvent mix them with the polyurethanes to compare the effect of different nanotubes treatments [31,32].

Nevertheless, to authors knowledge, any thorough study of PU nature influence on MWCNT reinforcing character has yet been addressed.

PU/MWCNT composites can be considered as ternary systems formed by the nanofiller, hard segments (HS) and soft segments (SS), each of which can vary in ratio, chemical composition and physical properties. The study of the polyurethanes phase morphology variation (which without filler is governed by HS and SS thermodynamic incompatibility) with the nanotubes inclusion and its effects onto mechanical performance, along with the understanding of thermodynamics of preferential association between nanotubes and PU phases should be considered of great importance to develop tailored PU/MWCNT composites.

In this work, a set of polyurethane/multiwalled carbon nanotubes (PU/MWCNT) with different HS content and nature was prepared by the solvent casting approach and buckypaper infiltration method for medium and high MWCNT concentrations, tested both mechanically and electrically and analysed by scanning electron microscopy (SEM). The morphology was also analysed by means of differential scanning calorimetry (DSC).

\section{Experimental}

\subsection{Preparation of PU matrices}

Polyurethane matrices were synthesised in our laboratory by the two shot polymerisation approach with $10,14,30,40,50 \mathrm{wt} \%$ hard segment formed by 1,6hexamethylene diisocyanate (HDI, Bayer, Desmour H) and 1,4-butanediol (BD) (Aldrich, $99 \%$ purity) and with $30 \mathrm{wt} \%$ of hard segment content formed by 4,4'- 
diphenylmethane diisocyanate (MDI, Bayer Desmour 44) and BD. Soft segment consisted on a polydiol, formed by polycaprolactone and polycarbonate blocks (PCL- $b$ PHMC- $b$-PCL, Ravecarb 111, Polimeri Europa). The preparation and properties of the polyurethanes is described elsewere [33]. The prepared polyurethanes are named indicating the employed diisocyanate in their hard segments and weight percent of hard segment in the polyurethane, as HDI-10 or MDI-30 for PU with $10 \mathrm{wt} \%$ hard segment based on HDI and $30 \mathrm{wt} \%$ hard segment based on MDI, respectively. The molar composition of all the polyurethanes is listed in Table 1.

\subsection{Nanotube acid pre-treatment.}

To favour nanotubes dispersion into solvents and polymer matrices, multiwalled carbon nanotubes (Nanocyl 3100, Belgium) were always purified with a $2 \mathrm{~h}$ strong acid treatment, consisting on a mixture of nitric and sulphuric acids in a ratio $\mathrm{HNO}_{3}: \mathrm{H}_{2} \mathrm{SO}_{4}$ of 1:3, in a sonic bath, obtaining acid treated multiwalled carbon nanotubes, MWCNT$\mathrm{COOH}$ with average lengths of $740 \mathrm{~nm}$, as described elsewere [34].

\subsection{Preparation of PU/MWCNT composites}

Composites with acid treated carbon nanotubes contents up to $20 \mathrm{wt} \%$ were prepared by solvent casting (SC) method [34]. Higher MWCNT loading composites were prepared by buckypaper (BP) infiltration of different concentrated polyurethanes tetrahydrofuran (THF) solutions and quantities, always with a controlled pressure of $200 \pm 20$ mbar. For polyurethanes above $30 \mathrm{wt} \%$ of hard segment the solvent employed was a mixture of THF:N,N-dimetylformamide (DMF) (1:1). Infiltration times were shorter for diluted solutions and smaller solution quantities. Typically $50 \mathrm{~mL}$ of $1 \mathrm{mg}$ $\mathrm{mL}^{-1}$ solution were infiltrated in about $12 \mathrm{~h}$, while $50 \mathrm{~mL}$ of $2 \mathrm{mg} \mathrm{mL}^{-1}$ needed around $24 \mathrm{~h}$, and $100 \mathrm{~mL}$ of a $1 \mathrm{mg} \mathrm{mL}^{-1}$ solution required around $20 \mathrm{~h}$ to infiltrate. When around $12 \mathrm{~h}$ of infiltration time was achieved, infiltrating pressure was reduced down to 
$50 \pm 10$ mbar in order to speed up the process.

\subsection{Characterisation methods}

Final nanotube volume fraction into the composites, $\phi$, was related to the nanotubes weight fraction, $X_{M W C N T}$, polymer density, $\rho_{\text {Polymer }}$, and nanotubes density,

$\rho_{M W C N T}$, using the following equation [35]:

$\phi=\frac{X_{M W C N T}}{X_{M W C N T}+\left(\rho_{M W C N T} / \rho_{\text {Polymer }}\right)-\left(\rho_{M W C N T} / \rho_{\text {Polymer }}\right) X_{M W C N T}}$

The films density was calculated by measuring precisely materials dimensions with a calliper (Mitutoyo, DIGIMATIC CD-15CP) and a low-torque digital micrometer (Mitutoyo) of pieces of about $7 \mathrm{~mm} \times 0.15 \mathrm{~mm} \times 2.5 \mathrm{~mm}$ and by weighting them on a thermo-gravimetrical analysis balance (Mettler Toledo, TGA/SDTA 851) with precision down to $\pm 0.001 \mathrm{mg}$. Typical weight values ranged between 0.5 and $4 \mathrm{mg}$.

Electrical DC measurements were carried out using a two probe current intensity voltage scan from 0 to $5 \mathrm{~V}$ employing a semiconductor analyser (Keithley 4200-SCS). Resistance was calculated from the slope of current intensity versus voltage (I-V) curves and averaged from three measurements. Distances between silver paint printed electrodes and specimen widths were measured with a digital calliper while thicknesses were measured using a low-torque digital micrometer in order to normalise resistance values into conductivity $\left(\mathrm{S} \mathrm{cm}^{-1}\right)$ values.

Tensile tests were performed with a constant crosshead speed of $100 \mathrm{~mm} \mathrm{~min}^{-1}$ for solvent cast composites and low MWCNT volume fraction infiltrated buckypapers, and with a crosshead speed of $1 \mathrm{~mm} \mathrm{~min}^{-1}$ for all buckypapers, with an initial crosshead distance of $8.5 \pm 0.5 \mathrm{~mm}$. Sample sizes were in the range of $80-140 \mu \mathrm{m}$ in thickness and of $2.5 \mathrm{~mm}$ in width. The equipment used (MTS insight 10) was provided with pneumatic grips (Advantage Pneumatic Grips) and with a loading cell of $250 \mathrm{~N}$. The 
results were averaged from a minimum of 3 specimens.

SEM analysis was performed using a JEOL JSM-7000F, with an accelerating voltage of $20 \mathrm{kV}$ and a distance of $9.0 \pm 0.5 \mathrm{~mm}$. Solvent cast composites with a MWCNT content lower than $20 \mathrm{wt} \%$, were coated with a thin gold layer of about 5-10 nm thickness with a Bal-Tec SCD-004 sputtering equipment.

DSC analysis of solvent cast composites was performed with scanning rates of $10{ }^{\circ} \mathrm{C} \min ^{-1}$ from $-60{ }^{\circ} \mathrm{C}$ to $200{ }^{\circ} \mathrm{C}$ using nitrogen as purge gas and an electric intracooler as cooling source. Heat flow was normalised to polyurethane weight fraction into composites.

The non-isothermal crystallisation experiments were carried out taking the samples to $220^{\circ} \mathrm{C}$ at $20^{\circ} \mathrm{C} \mathrm{min}{ }^{-1}$, leaving to melt for 4 min at that temperature and cooling down to $20^{\circ} \mathrm{C}$ at $2.5,5,10$ and $20^{\circ} \mathrm{C} \mathrm{min}-1$ of cooling rate.

\section{Results and discussion}

\subsection{MWCNT percolation network formation}

Sequentially increasing nanofiller addition to a hosting matrix leads to a situation in which at a particular concentration the filler forms a continuous percolated network. Upon this particular concentration a dramatic variation in some properties is expected due to the formation of two co-continuous phases which affect in different ways to the final composite properties. Detection of the critical MWCNT percolation volume fraction, $\phi_{\mathrm{p}}$, in a HDI-10 polyurethane, was performed graphically from the sharp increase of the electrical conductivity at $\phi_{\mathrm{p}}$, as seen in Fig. 1 . The bending point, upon which the increase of properties was sharper, occured at $\phi=0.025$ (4 wt $\%)$. The nanotubes disposition in relation to the PU matrix changes from below to above percolation threshold concentration, upon which nanotube-nanotube contacts become 
more and more important.

Electrical behaviour was modelled using the classic power scaling law for percolative systems [36]. The green curve has been drawn using this model with $\left\{\sigma_{0}, \phi_{\mathrm{p}}\right.$, $t\}=\left\{20 \mathrm{~S} \mathrm{~cm}^{-1}, 0.025,2.73\right\}\left[\sigma_{0}\right.$ being the electrical DC conductivity of the $100 \mathrm{wt} \%$ MWCNT buckypapers and $t$ the value obtained from the slope of the experimental $\log \sigma_{\mathrm{DC}}$ vs. $\log \left(\phi-\phi_{\mathrm{p}}\right)$ curve]. This curve has been extrapolated towards $\phi=0$, introducing the conductivity of the neat polyurethane as initial value of $\sigma_{\mathrm{DC}}$.

Composites prepared by the infiltration method presented slightly higher electrical conductivities than those based on the solvent cast approach, probably due to a more direct contact between nanotubes in the network junction points.

\subsection{Influence of hard segment content.}

The effect of MWCNT-COOH addition on the elongation to break, $\varepsilon_{\max }$, normalised tensile strength, $\sigma_{\mathrm{c}} / \sigma_{\mathrm{m}}$, and elastic modulus, $E_{\mathrm{c}} / E_{\mathrm{m}}$, of composites based on polyurethanes based on HDI diisocyanate with different hard segment content is gathered in Fig. 2. The common feature for all types of composites is that mechanical properties evolution was virtually invariable or very small up to the nanotube percolation threshold concentration.

As seen in Fig. 2a-c this spike on the property versus $\phi$ behaviour, occurred at higher nanotube concentration for composites whose matrices contained higher amount of hard segment. The ductility decrease results further suggests a preferential interaction of nanotubes with polyurethane hard segments. Being the soft domains responsible of polyurethanes extensibility, it is understandable that polyurethanes with bigger amount of soft segment might have nanotubes hosted within soft domains at lower nanotube concentrations than polyurethanes with higher amounts of hard segment. This fact is 
also observed in Fig. 3a, where the decrease in ductility is represented for several polyurethane hard segment contents against nanotube weigh fraction. In polyurethanes with higher hard segment content the decrease in extensibility occurred at higher nanotube loadings because the nanotubes are primarily interacting with hard domains, which do not contribute primarily to material extensibility.

Modulus enhancements as calculated for each HDI based polyurethane composite series are gathered in Fig. 3b. It is seen that the tendency of this value (slope of $E_{\mathrm{c}}$ vs. $\phi$ ) trends to increase with polyurethane hard segment content, with a dramatic increase for HDI-30 system. These values, when normalised over the matrices elastic modulus, $E_{\mathrm{m}}$, provide the relative modulus enhancement (slope of $E_{\mathrm{c}}$ vs. $\phi$ divided over matrix elastic modulus), which values are gathered in Fig. 3c. As seen, the enhancements tend to decrease with hard segment content.

The interfacial shear strengths, $\tau_{\mathrm{c}}$, as calculated from the slope of $\sigma_{\mathrm{c}}$ vs. $\phi$ data for each polyurethane series, using a common Bowyer-Bader model for aligned fibres in the manner described elsewere [34], are gathered in Fig. 3d. As can be seen, the maximum value was achieved utilising HDI-30 as a matrix. The bell type pattern of the data can be related to the match between polyurethanes surface tension, $\gamma$, as calculated by water contact angle measurements [33], that occurs around a polyurethane composition of $30 \mathrm{wt} \%$ hard segment $\left(42.6 \mathrm{~mJ} \mathrm{~m}^{-2}\right)$, with that of the carbon nanotubes of $40 \mathrm{~mJ} \mathrm{~m}^{-2}$ reported by Bergin et al [37].

The ductility reduction fact can be explained taking into account the nanofiller and hard domain relative sizes. These particular polyurethanes hard domains have an average diameter of $\sim 15 \mathrm{~nm}$ with interdomain distances in the range of 14-32 $\mathrm{nm}$ [16] (see Fig. 1). On the other hand the nanotubes have been measured to have diameters of 
$\sim 12 \mathrm{~nm}$ and lengths of $\sim 740 \mathrm{~nm}$ on average [34]. Therefore nanotube length may be more than enough to interconnect different hard domains and therefore hinder soft segments ductility, as represented in Fig. 4. This fact strongly supports the idea that nanoconfinement into polyurethane hard domains is an important factor to retain the ductility [38], as has been suggested to be the case for natural silk [38,39].

The fracture surface of composites with $20 \mathrm{wt} \%$ MWCNT-COOH and HDI-10, HDI-30 and HDI-50 matrices were studied by SEM. Results are gathered in Fig. 5. The increase of matrix hard segment content led to more brittle surface pattern, characterised for a more homogeneous fringe sizes and distributions. In the first row (Fig. 5a,b) the HDI-10 system is shown at different magnifications, revealing high deformations and tubular structures protruding from the bulk, which could be due to bundled nanotubes aligned along the stress direction, wrapped by HDI-10 matrix. No isolated nanotubes were observed for the HDI-10 system. In HDI-30 system (Fig. 5c,d) no isolated nanotubes were observed, but some brighter dots protruding from the bulk were observed, which could be related to nanotubes tips appearing along the surface. In HDI50 system the nanotubes were clearly seen (Fig. 5f) protruding perpendicularly to the fracture surface. This result suggests that despite the closer values between Hildebrand global solubility parameters [40], $\delta$, of MWCNT-COOH to polyurethane hard segments (Table 2), the overall matrix surface tension may be the determinant factor to account for the stress transfer between the polyurethane matrix and the nanotubes.

As mentioned in the introduction section, PU composites can be regarded as ternary systems in which their complexity arises not only by the presence of a nanofiller but also for the changes in morphology of PU hard phase and soft phases with a third component addition. Therefore to study morphology evolution with MWCNT addition calorimetric measurements were performed. Heating scans of composites prepared with 
the polyurethanes based on HDI with 10, 30 and $50 \mathrm{wt} \%$ hard segment contents are shown in Fig. 6a-c, respectively. In Fig. 6a it can be seen that the endotherm appearing with low hard segment content PU around $50{ }^{\circ} \mathrm{C}$, related to hard segments interacting with soft segments, which is activated at hard segment glass transition, $T_{\mathrm{Hard}:: \text { Soft }}$ is decreased as nanotube content increases, while another peak appears at higher temperatures, $T_{\mathrm{Hard}: \cdots \mathrm{MWCNT}}$, corresponding to interaction of hard segments with nanotubes. This area is coloured with dark brown. This is related to the lower mobility of hard segments and the hindrance to develop hard segments-soft segments interactions. The increase in the transition endset suggests some hard segment-nanotube interactions stabilise the dynamic thermal properties of the composites, as has been reported in our previous paper [34]. The crystallisation exotherm of soft segments, coulored with light blue, with a peak at $-28{ }^{\circ} \mathrm{C}$, decreased as nanotube content increased, suggesting also a restricted mobility of soft segments. In PU with higher hard segment content such as HDI-30 and HDI-50, the hard segments are able to develop more phase separated structures which have higher temperatures endotherms associated with hard segment crystals. In Fig. 6b,c for HDI-30 and HDI-50, respectively, this endotherm is coloured with light orange and in both cases is reduced with nanotubes incorporation while it is seen a concomitant increment of the heat capacity change related to amorphous hard segments at the glass transition at $T_{g \text { Hard. This fact suggests nanotubes }}$ interacted with hard segments reducing their crystallising capability and leading to more amorphous hard phase. The transition corresponding to amorphous hard segments increased, once again confirming the presence of more independent segments in a noncrystalline state as nanotube content increased (further confirmation by DSC in the supporting information, Fig.S1).

Further confirmation of nanotube effects on domains crystallinity was 
demonstrated by dynamic DSC crystallisation measurements. In Fig. 7a the nucleating effect of nanotubes over polyurethane hard segments is seen as an increase in the crystallisation exotherm peak of about $11^{\circ} \mathrm{C}$ in these cooling scans of composites prepared with HDI-50. This fact suggests that hard segments interacted with nanotubes and at the same time they reduced their crystallinity degree. Performing similar experiments under sub-zero temperature the same nucleating effect was found for soft segments in HDI-10.

In Fig. 7b typical modified Avrami plots [41] for non-isothermal crystallisation experiments, carried out at $2.5^{\circ} \mathrm{C} \mathrm{min}^{-1}$ cooling rate, are presented, indicating the differences in slope, $n_{1}$, of the curves, which varied from 38 for the pure HDI-50 to 14 for the composite containing $3 \mathrm{wt} \%$ of nanotubes. This indicates a dramatic change in hard segment crystallisation mechanism [42]. The $y$-axis intercept, related with crystallisation rate, increased from -57 to -19 , from the HDI-50 to the nanocomposite, indicating a big increase in hard segment crystallisation rate with the addition of MWCNT. This fact contradicts results obtained for PA6/MWCNT [43] and Nylon6/Foliated graphite [44] composites in which a decrease in both crystallisation rate and crystalline degree were found. Differences could arise from the difference in the matrix employed. Fig. 7c represents schematically the proposed nucleating effect of nanotubes over hard segments at the same time they also reduce the hard segment crystalline degree by avoiding hard segment mobility and self assembling (Melting enthalpies are shown in the support information, Fig. S1).

All the results from both the solvent casting method and buckypaper infiltration approach were now gathered to try to create a ternary composition diagram, as exposed in the introduction. Fig. 8 presents a ternary diagram in which the compositions of SC composites made up with HDI-10, HDI-30 and HDI-50 are presented along with some 
of the derived high loading infiltrated BP nanocomposite compositions. Obtained data for some representative systems is also included. It is seen that a wide range of properties can be obtained and varied by the proper selection of the polyurethanes hard segment to soft segment ratio, but also by the addition of MWCNT. This tuneability of mechanical properties permits these ternary systems (e.g: HDI-BD hard segments, PCL $b$-PHMC- $b$-PCL and MWCNT) to fulfil the demand of a different range of applications.

The complexity of using ternary diagrams to relate composition with properties, is highlighted when some other aspects such as processing techniques [34], thermal treatments [45], solvent choice [46] or nanotubes functionalisation and aspect ratio are considered. But as will be discussed next, variation of polyurethane hard segment nature also has important influence on some nanocomposite final mechanical performance features such as ductility or mechanical reinforcement.

\subsection{Influence of hard segment nature}

The neat HDI based polyurethanes had high modulus/hard segment content ratio. With just $10 \mathrm{wt} \%$ hard segment into the polyurethane the tensile modulus was $8 \pm 0.6$ MPa. There are other examples in literature [15] in which such a modulus value is just obtained using about $30 \mathrm{wt} \%$ of aromatic MDI and BD as hard segment constituents, and using a polyol of about the same molecular weigh as in this work. This is related to the higher crystallinity of HDI/BD hard segment based polyurethanes in comparison to those based on MDI/BD [33]. Therefore an advantage of using this high crystalline polyurethane with low hard segment contents is that while providing fairly good modulus it retains the benefits of a highly ductile material.

For comparison of MWCNT-COOH reinforcement into a HDI based polyurethane with those based on MDI, a hard segment ratio of $30 \mathrm{wt} \%$ was chosen. 
The effects of nanotube loading on mechanical properties for both HDI-30 and MDI-30 polyurethanes are gathered in Fig. 9. Table 3 gathers the reinforcement parameters along with surface tension values of composites prepared with HDI-30 and MDI-30 as matrices and different nanotubes contents. It is seen that the relative modulus enhancement is higher for the MDI based polyurethane than for the based on HDI, this fact being related to the differences between matrices crystallinity.

Surprisingly MDI-30 polyurethane retained its ductility for higher nanotube volume fractions than HDI-30, while modulus enhancement begun to occur at lower nanotube volume fractions than for HDI-based polyurethane. It is noteworthy that for the series of HDI-based polyurethanes with varied hard segment content the percolation threshold effects affecting both ductility and modulus enhancement scaled up with polyurethanes crystallinity (increase in hard segment content). MDI-30 has a lower degree of crystallinity than HDI-30 but the effects on ductility were perceived at higher nanotube concentrations than for HDI-30.

Contrarily, for MDI-30 systems the strength reached a maximum around the percolation threshold concentration and trend to decrease above it. This fact could be related to the lower surface tension that MDI-based polyurethanes present [33] leading to favoured but weak nanotube-nanotube interactions. Despite having MDI/BD hard segment higher solubility parameter than the HDI-BD hard segments (Table 2) and its composites higher interfacial shear strength (Table 3), the un-match between the materials overall surface tension with that of the nanotubes could be the determinant factor influencing the loss in reinforcement at high nanotube loadings.

The higher observed absolute value of reinforcement, $\mathrm{d} \sigma_{\mathrm{c}} / \mathrm{d} \phi$, listed in Table 3 for MDI-30 composites could be related to a stronger interaction between aromatic MDI/BD hard segment with nanotubes surface via $\pi$ - $\pi$ stacking in addition to common 
polar and hydrogen bond interactions, as comparison with the aliphatic HDI/BD hard segments.

\section{Conclusions}

Control of the complexity of PU chemistry and physical properties of their derived composites may lead to new high performance hierarchically assembled composites. Addition of nanosized fillers with outstanding properties, such as MWCNT could be regarded as an interesting approach for the purpose of creating new elastomeric materials with enhanced mechanical and electrical properties.

The reduction of ductility with MWCNT addition could be related to the relative MWCNT big sizes in comparison to PU hard domains, being, as demonstrated also by other groups, an important factor to target polyurethanes hard domains in order to obtain improvement on mechanical properties without a consequent reduction in ductility and toughness, therefore resembling the performance of materials such as natural silk.

\section{Acknowledges}

Financial support from Spanish Ministerio de Ciencia e Innovación (TME-200801156) and Basque Country Governments in the frame of CIC-inanoGUNE-ETORTEK 0911, Grupos Consolidados (IT-365-07) and SAIOTEK S-PE09UN07 is gratefully acknowledged. The authors also wish to acknowledge SGIker, General Research Services from the University of the Basque Country and specially to the Macroconducta-Mesoestructura-Nanotecnología and Microscopía Electrónica y Microanális de Materiales units for their help with the AFM and SEM, respectively. 


\section{References}

[1] Ajayan PM, Stephan O, Colliex C, Trauth D. Aligned carbon nanotube arrays formed by cutting a polymer resin—nanotube composite. Science 1994; 265: 1212.

[2] Advani SG. Processing and properties of nanocomposites. Shaffer M, Sandler J. Singapore: World Scientific Publishing; 2007, p 1.

[3] Xu L, Nakajima H, Manias E, Krishnamoorti R. Tailored Nanocomposites of Polypropylene with Layered Silicates. Macromolecules 2009; 42: 3795.

[4] Sreekumar TV, Liu T, Min BG, Guo H, Kumar S, Hauge RH, Smalley RE. SWNT/PAN Composite Fibers. Advanced Materials 2004; 16: 58.

[5] Dalton AB, Collins S, Muñoz E, Razal JM, Ebron VH, Ferraris JP, Coleman JN, Kim BG, Baughman RH. Super-tough carbon-nanotube fibers. Nature 2003; 423:703.

[6] Zeng JJ, Saltysiak B, Johnson WS, Schiraldi DA, Kumar S. Processing and properties of poly(methyl methacrylate)/carbon nano fiber composites. Composites Part B: Engineering 2004; 35: 173.

[7] Grunlan JC, Mehrabi AR, Bannon MV, Bahr JL. Water-based single wallednanotubefilled polymer composite with an exceptionally low percolation threshold. Advanced Materials 2004; 16: 150.

[8] Benoit JM, Corraze B, Lefrant S, Blau WJ, Bernier P, Chauvet O. Transport properties of PMMA-carbon nanotubes composites. Synthetic Metals 2001; 121: 1215.

[9] Biercuk MJ, Llaguno MC, Radosavljevic M, Hyun JK, Johnson AT, Fisher JE. Carbon nanotube composites for thermal management. Applied Physics Letters 2002; 80: 2767.

[10] Shenogin S, Xue LP, Ozisik R, Keblinski P, Cahill DG. Role of thermal boundary resistance on the heat flow in carbon-nanotube composites. Journal of Applied Physics 2004; 95: 8136.

[11] Guo H, Sreekumar TV, Liu T, Kumar S. Structure and properties of polyacrylonitrile/single wall carbon nanotube composite films. Polymer 2005; 46: 3001.

[12] Ichida M, Mizuno S, Kataura H, Achiba Y, Nakamura A. Anisotropic optical properties of mechanically aligned single-walled carbon nanotubes in polymer. Applied Physics A, Materials Science and Processing 2004; 78: 1117.

[13] Hepburn, C. Polyurethane Elastomers, $2^{\text {nd }}$ ed. Elsevier: Essex. 1992: p. 1.

[14] Gogolewski S. Selected topics in biomedical polyurethanes. A review. Colloid and Polymer Science 1989; 267: 757.

[15] Xia H, Song M. Preparation and characterization of polyurethane-carbon nanotube composites. Soft Matter 2005; 1: 386.

[16] Fernández-d'Arlas B, Rueda L, Fernández R, Khan U, Coleman JN, Mondragon I, Eceiza A. Inverting polyurethanes synthesis: Effects on nano/micro-structure and mechanical properties. Soft Materials 2011; 9:79.

[17] Webster TJ, Waid MC, Mackenzie JL, Price RL, Ejiofor JU. Nanobiotechnology: Carbon nanofibers as improved neural and orthopedic implants. Nanotechnology 2004; 15: 48.

[18] Nicolau DV. Biomedical Applications of Micro- and Nanoengineering II. Williams CM, Nash MA, Poole-Warren LA. Proceedings of the SPIE, Sydney, 2005; vol. 5651; p. 329-335. 
[19] Meng J, Kong H, Xu HY, Song L, Wang CY, Xie SS. Improving the blood compatibility of polyurethane using carbon nanotubes as fillers and its implications to cardiovascular surgery. Journal of Biomedical Materials Research 2005; 74A: 208.

[20] Jung YC, Kim HH, Kim YA, Kim JH, Cho JW, Endo M, Dresselhaus MS. Optically Active Multi-Walled Carbon Nanotubes for Transparent, Conductive Memory-Shape Polyurethane Film. Macromolecules 2010; 43: 6106.

[21] Chen W, Tao X, Liu Y. Carbon nanotube-reinforced polyurethane composite fibers. Composites Science and Technology 2006; 66: 3029.

[22] Koerner H, Liu W, Alexander M, Mirau M, Dowty H, Vaia RA. Deformationmorphology correlations in electrically conductive carbon nanotube thermoplastic polyurethane nanocomposites. Polymer 2005; 46: 4405.

[23] Sahoo NP, Jung YC, Yoo HJ, Cho JW. Effect of functionalized carbon nanotubes on molecular interaction and properties of polyurethane composites. Macromolecular Chemistry and Physics 2006, 207: 1773.

[24] Kwon JY, Kim HD. Preparation and properties of acid-treated multiwalled carbon nanotube/ waterborne polyurethane nanocomposites. Journal of Applied Polymer Science 2005; 96: 595.

[25] Xiong J, Zheng Z, Qin X, Li M, Li H, Wang X. The thermal and mechanical properties of a polyurethane/multi-walled carbon nanotube composite. Carbon 2006; 44: 2701.

[26] Xia H, Song M. Preparation and characterisation of polyurethane grafted single walled carbon nanotubes derived polyurethane nanocomposites. Journal of Materials Chemistry 2006; 16: 1843.

[27] Jung YC, Sahoo NG, Cho JW. Polymeric nanocomposites of polyurethane block copolymers and functionalized multi-walled carbon nanotubes as crosslinkers. Macromolecular Rapid Communication 2006; 27: 126.

[28] Kwon J, Kim H. Comparison of the properties of waterborne polyurethane/multiwalled carbon nanotube and acid-treated multiwalled carbon nanotube composites prepared by in situ polymerisation. Journal of Polymer Science: Part A: Polymer Chemistry 2005; 43: 3973.

[29] Xu M, Zhang T, Gu B, Wu J, Chen Q. Synthesis and properties of novel polyurethane-urea/multiwalled carbon nanotube composites. Macromolecules 2006; 39: 3540 .

[30] Kuan HC, Ma CCM, Chang WP, Yuen SM, Wu HH, Lee TM. Synthesis, thermal, mechanical and rheological properties of multiwalled carbon nanotube/waterborne polyurethane nanocomposite. Composites Science and Technology 2005; 65: 1703.

[31] Lee CH, Liu JY, Chen SL, Wang YZ. Miscibility and properties of acid-treated multiwalled carbon nanotubes/polyurethane nanocomposites. Polymer Journal 2007; 39: 138.

[32] Deng J, Zhang X, Wang K, Zou H, Zhang Q, Fu Q. Synthesis and properties of poly(ether urethane) membranes filled with isophorone diisocyanate-grafted carbon nanotubes. Journal of Membrane Science 2007; 288: 261.

[33] Fernández-d'Arlas B, Rueda L, de la Caba K, Mondragon I, Eceiza A. Microdomain composition and properties differences of biodegradable polyurethanes based on MDI and HDI Polymer Engineering and Science 2008; 48: 519.

[34] Fernández-d'Arlas B, Khan U, Rueda L, Martin L, Ramos JA, Coleman JN, González, ML, Valea A, Mondragon I, Corcuera MA, Eceiza A. Study of the mechanical, electrical nand morphological properties of PU/MWCNT composites obtained by two different processing routes. Composites Science and Technology (under review). 
[35] Thostenson ET, Chou TW. On the elastic properties of carbon nanotube-based composites: modeling and characterization. Journal of Physics D: Applied Physics 2003; 36: 573.

[36] Frisch HL, Hammersley JM. Percolation processes and related topics. Journal of the Society for Industrial and Applied Mathematics 1963; 11: 894.

[37] Bergin SD, Nicolosi V, Streich PV, Giordani S, Sun Z, Windle AH, Ryan P, Niraj NP, Wang ZT, Carpenter L, Blau WJ, Boland JJ, Hamilton JP, Coleman JN. Towards solutions of single-walled carbon nanotubes in common solvents. Advanced Materials 2008, 20: 1876.

[38] Liff SM, Kumar M, McKinley GH. High-performance elastomeric nanocomposites via solvent-exchange processing. Nature Materials 2007; 6: 76.

[39] Keten S, Xu Z, Ihle B, Buehler M. Nanoconfinement controls stiffness, strength and mechanical toughness of $\beta$-sheet crystals in silk. Nat. Mater. 2010; 9: 359.

[40] V. Krevelen. Properties of polymers. $3^{\text {rd }}$ ed. Elsevier Science: Amsterdam. 1990: p 189.

[41] Ma Y, Hu G, Ren X, Wang B. Non-isothermal crystallization kinetics and melting behaviors of nylon 11/tetrapod-shaped $\mathrm{ZnO}$ whisker ( $\mathrm{T}-\mathrm{ZnOw}$ ) composites. Materials Science and Engineering: A 2007; 460: 611.

[42] Joshi M, Butola BS. Studies on nonisothermal crystallization of HDPE/POSS nanocomposite. Polymer 2004; 45: 4953.

[43] Meng H, Suiy G, Xie G, Yang R. Non-isothermal crystallization kinetics of polyamide 6/diamine-modifed MWNTs nanocomposite. Journal of Materials Science and Technology 2009; 25: 145.

[44] Weng W, Chen G, Wu D. Crystallization kinetics and melting behaviors of nylon 6/foliated graphite nanocomposites. Polymer 2003; 44: 8119.

[45] Tercjak A, Serrano E, Mondragon I. Multifunctional thermally reversible nanostructured thermosetting materials based on block copolymers dispersed liquid crystal. Macromolecular Rapid Communication 2007; 28: 937.

[46] Khan U, Ryan K Blau WJ, Coleman JN. The effect of solvent choice on the mechanical properties of carbon nanotube-polymer composites. Composites Science and Technology 2007; 67: 3158. 


\section{FIG. CAPTIONS}

Fig. 1. MWCNT/PU Percolative network detection and DC electrical conductivity. (๘) Data obtained with solvent cast technique produced composites. ( $\mathbf{A}$ ) Data obtained for buckypapers. The green line represents the general percolative model.

Fig. 2. Mechanical properties of composites: a) Strain at break, b) normalised strength and c) normalised elastic modulus of composites prepared with HDI polyurethanes as a function of hard segment and nanotube concentration.

Fig. 3. a) Extensibility as a function of hard segment content and nanotube weight fraction. b) Modulus enhancement as a function of polyurethane hard segment. c) Normalised modulus enhancement as a function of polyurethane hard segment content. d) Interfacial shear strength as calculated using a Bowyer-Bader model for aligned short fibres, as a function of polyurethane hard segment content.

Fig. 4. a) Model of a polyurethane network formed by hard domains (yellow) interconnected by the soft flexible chains (brown ropes), non stretched and b) stretched along the blue row direction. c) Long nanotubes inclusion interacting with hard segments at room temperatures may reduce the ductility of soft segments, as depicted in (d).

Fig. 5. Scanning electron microscopy analysis of fracture surfaces for composites with $20 \mathrm{wt} \%$ MWCNT and different HS contents: a, b) HDI-10; c, d) HDI-30 and e, f) HDI-50. Scale bars in first and second column are of $10 \mu \mathrm{m}$ and $1 \mu \mathrm{m}$, respectively.

Fig. 6. DSC heating scans of composites with the indicated weight fraction (wt $\%$ ) of MWCNT. a) HDI-10, b) HDI-30 and c) HDI-50 as composites matrices.

Fig. 7. a) Non-isothermal crystallisation scans of HDI-50 composites with the indicated carbon nanotube content. b) Modified Avrami plots for a non-isothermal crystallisation of HDI-50 and a HDI-50 nanocomposite with $3 \mathrm{wt} \%$ of MWCNT, at $2.5^{\circ} \mathrm{C} \min ^{-1}$ cooling rate. c) Sketch of the nucleating effect of nanotubes and crystallinity reduction.

Fig. 8. Ternary composition diagram of solvent cast and infiltrated buckypapers composites. Mechanical properties of composites are summarised as function of carbon nanotubes, hard segment, and soft segment weigh fractions. Values of composites elastic modulus, tensile strength and elongation to break along values of density and DC conductivity for some materials are included.

Fig. 9. Mechanical properties versus nanotube loading on polyurethanes based on HDI $(\boldsymbol{\Delta})$ and MDI (O). The dotted blue and red lines corresponds to the Bowyder-Bader model prediction for the HDI-30 and MDI-30 polyurethanes based composites respectively. 


\section{TABLES}

Table 1. Summary of prepared matrices chemical composition and reactants molar ratio.

\begin{tabular}{cccc}
\hline Abbreviations & Isocyanate & Wt\% Hard segment & Polyol: BD: Diisocyanate \\
\hline HDI-10 & HDI & 10 & $4: 1: 5$ \\
HDI-17 & HDI & 17 & $1: 1: 2$ \\
HDI-30 & HDI & 30 & $1: 3: 4$ \\
HDI-40 & HDI & 40 & $1: 7: 8$ \\
HDI-50 & HDI & 50 & $1: 2: 3$ \\
MDI-30 & MDI & 30 &
\end{tabular}

Table 2. Hildebrand solubility parameters of MWCNT-COOH along those calculated for the polyurethanes segments.

\begin{tabular}{lc}
\hline Material & $\boldsymbol{\delta}$ \\
\hline MWCNT-COOH & $\left(\mathbf{J}^{\mathbf{1} / 2} \mathbf{c m}^{-\mathbf{3} / 2}\right)$ \\
\hline - (HDI-BD)- & $25^{\varnothing}$ \\
- (MDI-BD)- & $23.0^{*}$ \\
PCL- $\boldsymbol{b}$-PHMC- $\boldsymbol{b}$-PCL & $25.3^{*}$ \\
\hline${ }^{\emptyset}$ Assumed to be higher than DMF (which is a good \\
pristine nanotubes solvent), for the introduction of \\
polar groups upon acid treatment. \\
${ }^{*}$ Calculated using Feedors molar volumes and \\
\multicolumn{2}{l}{ Hoftyzer-Van Krevelen method. }
\end{tabular}


Table 3. Reinforcing parameters and surface tension values of MDI-30 and HDI-30 matrices loaded with mulltiwalled carbon nanotubes

\begin{tabular}{ccccccc}
\hline Matrix & $\begin{array}{r}\mathbf{d} E_{\mathrm{c}} / \mathbf{d} \phi \\
(\mathbf{M P a})\end{array}$ & $\left(\mathbf{d} E_{\mathrm{c}} / \mathbf{d} \phi\right) \mathbf{E}_{\mathbf{m}}{ }^{-1}$ & $\begin{array}{c}\mathbf{d} \sigma_{\mathrm{c}} / \mathbf{d} \phi \\
(\mathbf{M P a})\end{array}$ & $\left(\mathbf{d} \sigma_{\mathrm{c}} / \mathbf{d} \phi\right) \sigma_{\mathbf{m}}^{-1}$ & $\begin{array}{c}\tau_{\mathrm{c}} \\
(\mathbf{M P a})\end{array}$ & $\begin{array}{c}\gamma \\
\left(\mathbf{m J} \mathbf{~ m}^{-2}\right)\end{array}$ \\
\hline MDI-30 & $842 \pm 62$ & 80.2 & $289 \pm 61$ & 12.2 & 5.0 & 13.8 \\
HDI-30 & $1068 \pm 74$ & 10.3 & $221 \pm 16$ & 14.3 & 3.8 & 42.6 \\
\hline
\end{tabular}




\section{FIGURES}

Fig.1

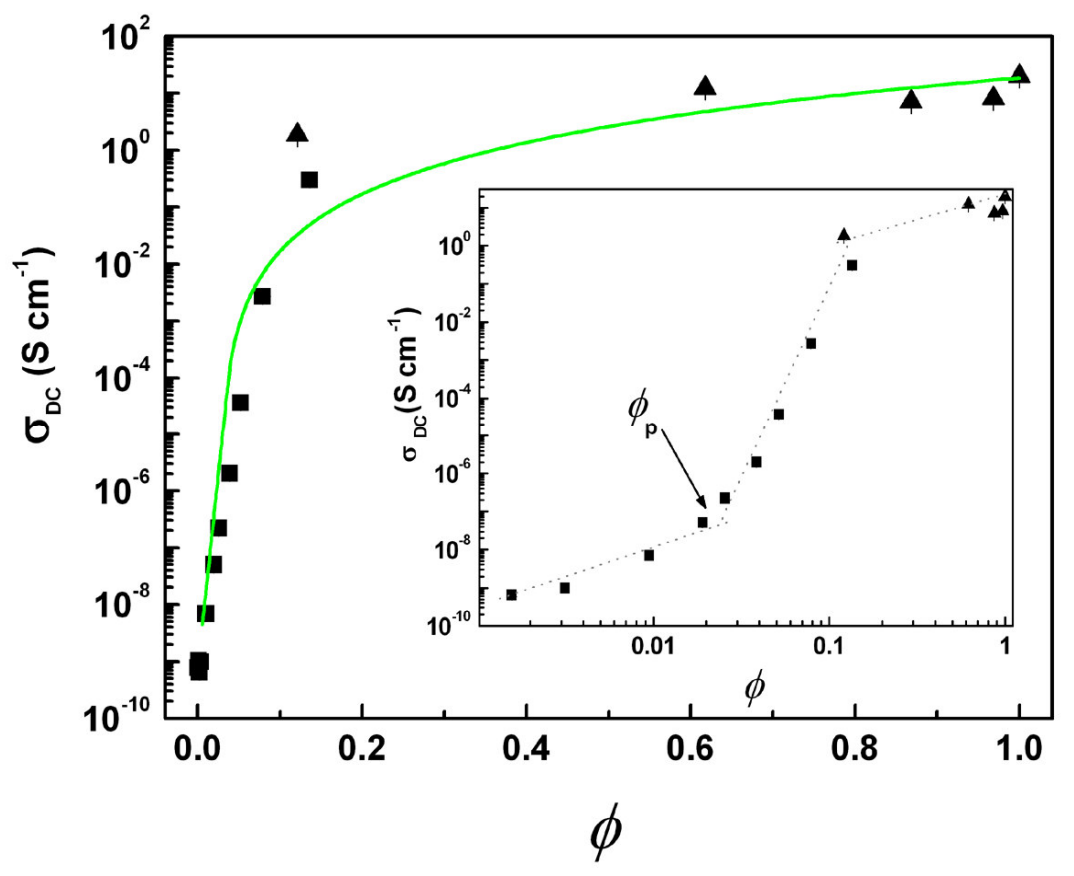


Fig.2

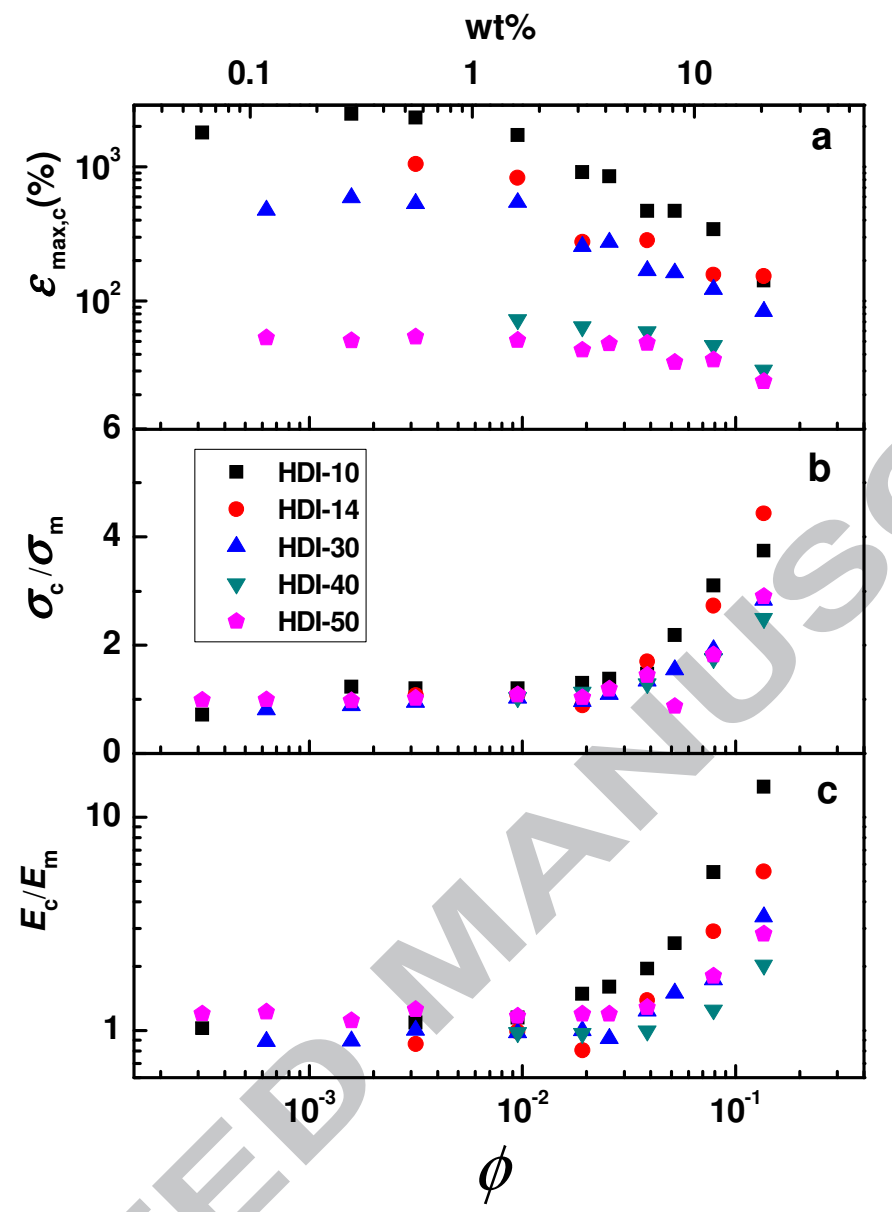


Fig.3
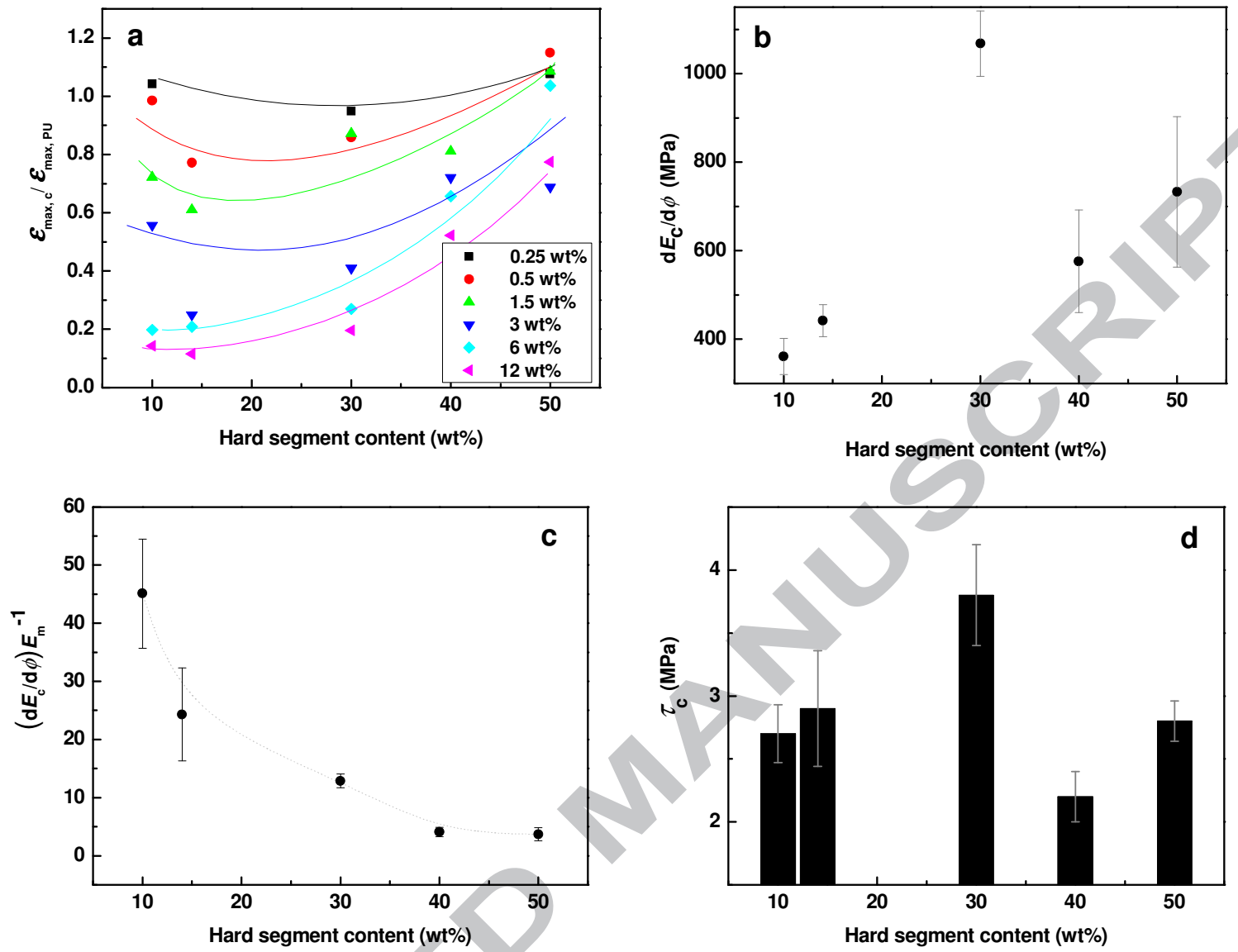

Fig.4
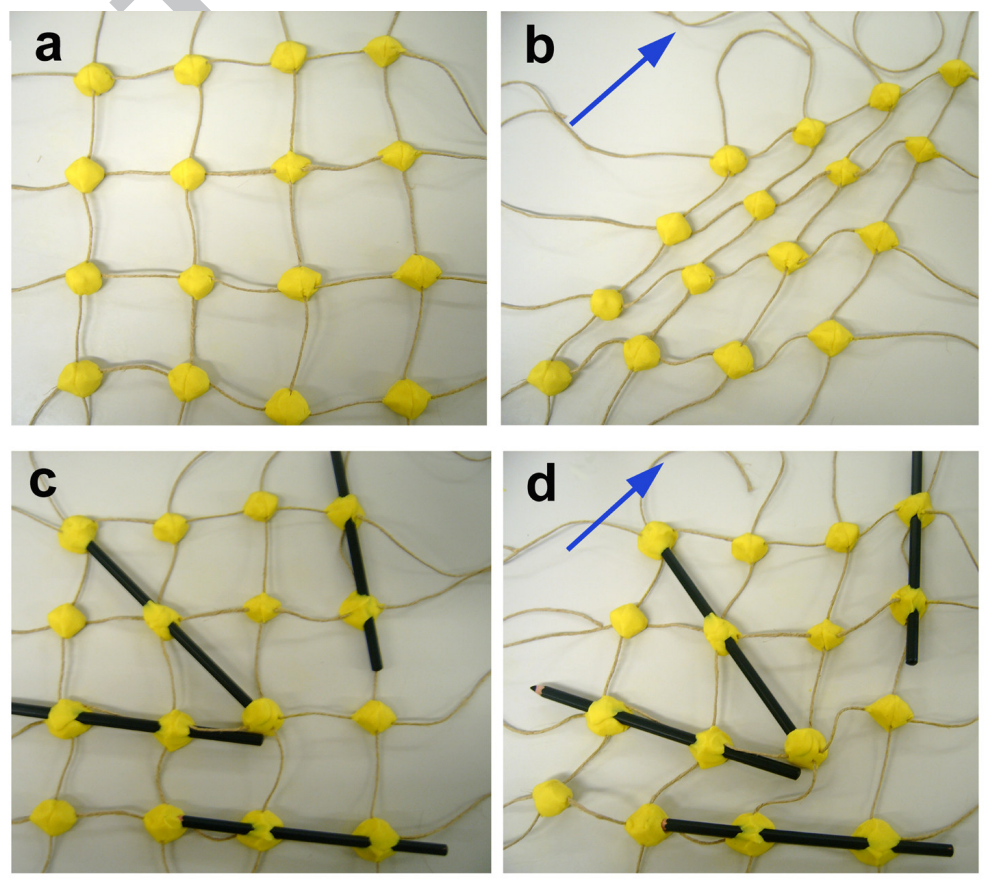
Fig.5
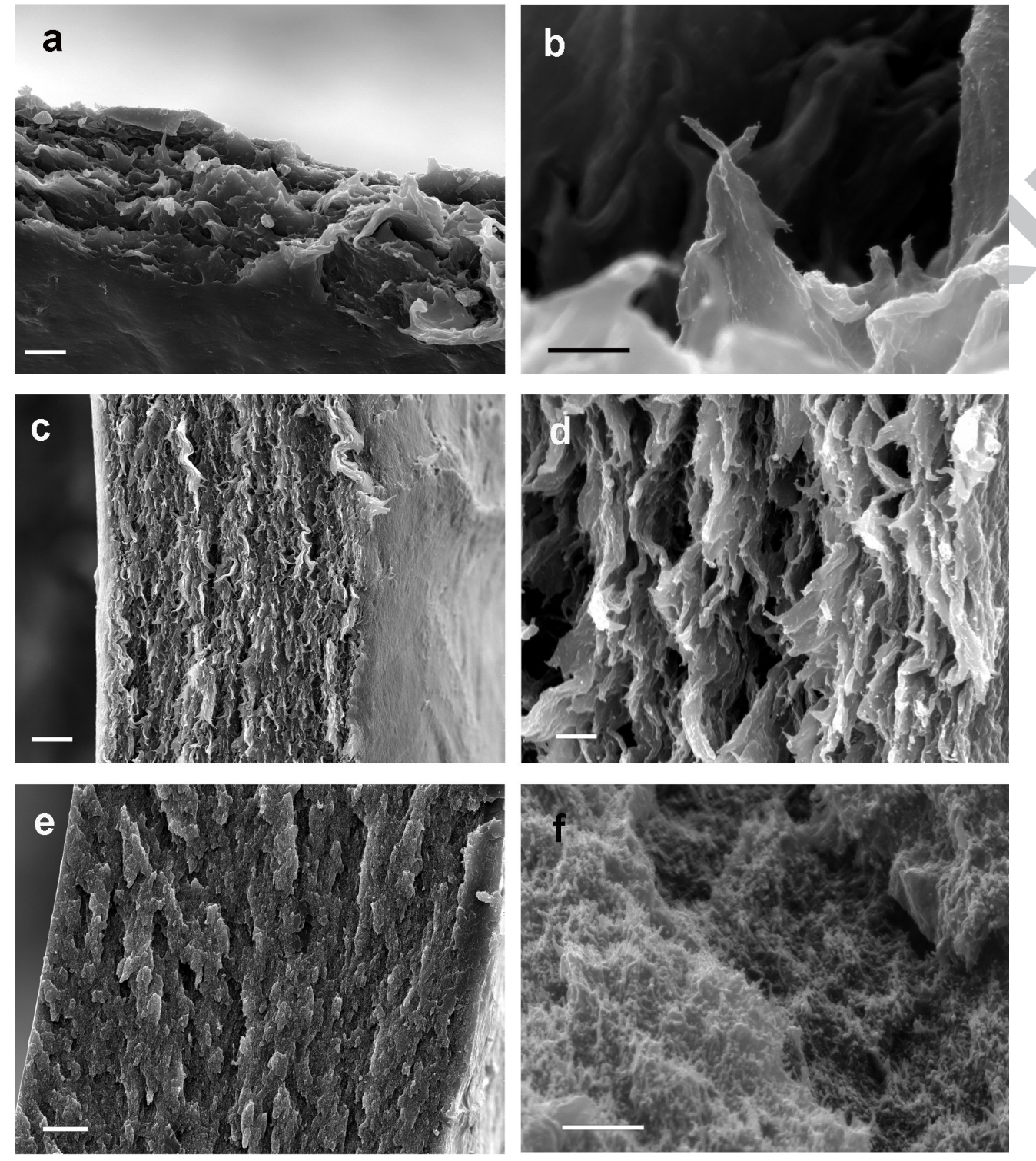
Fig.6
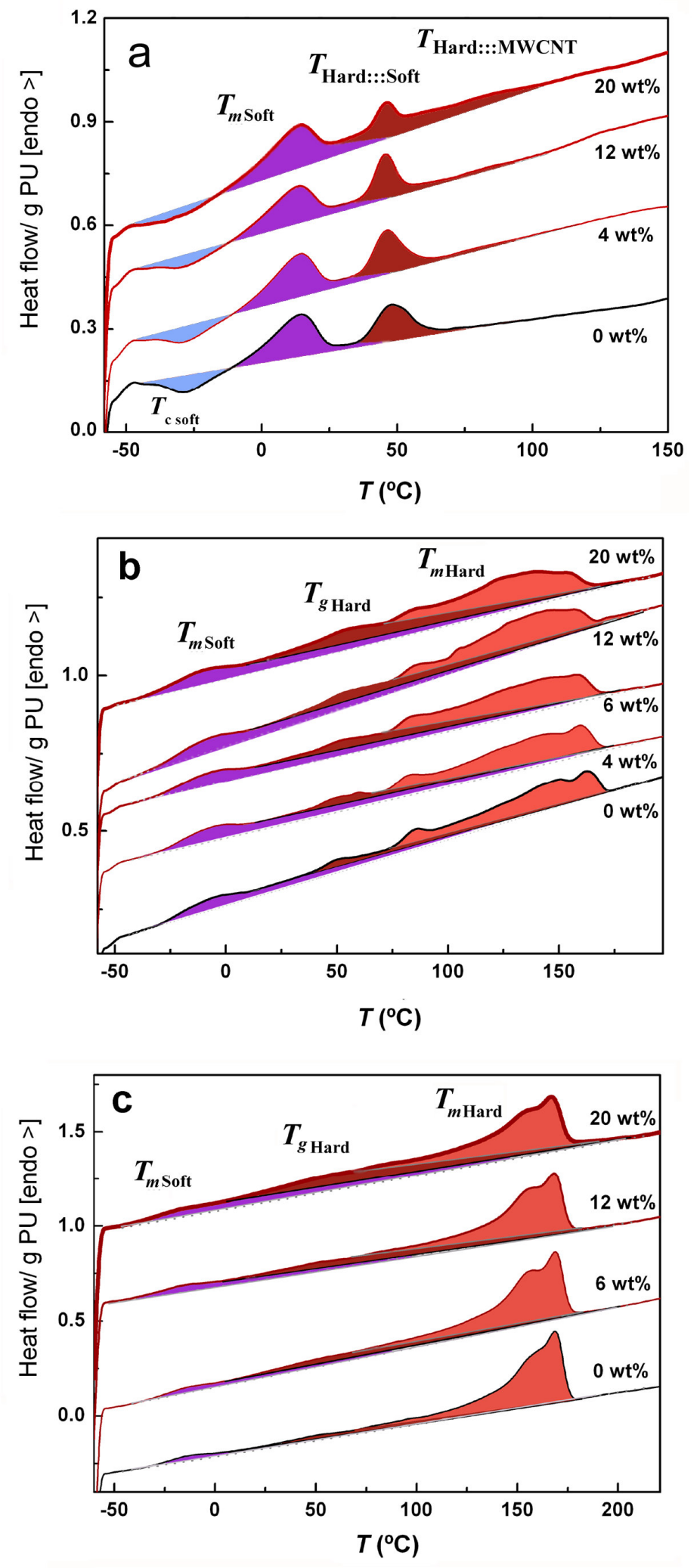
Fig.7
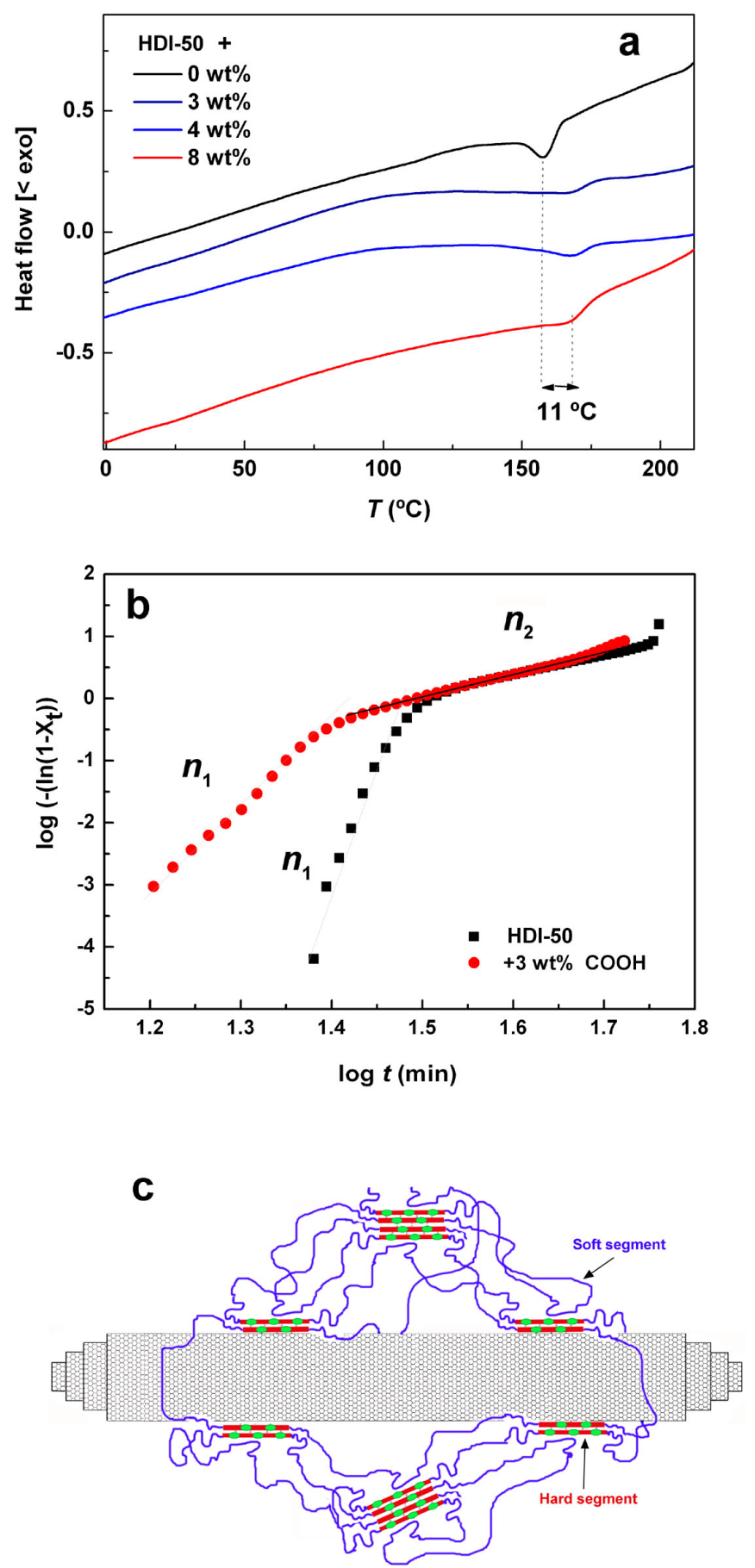
Fig.8

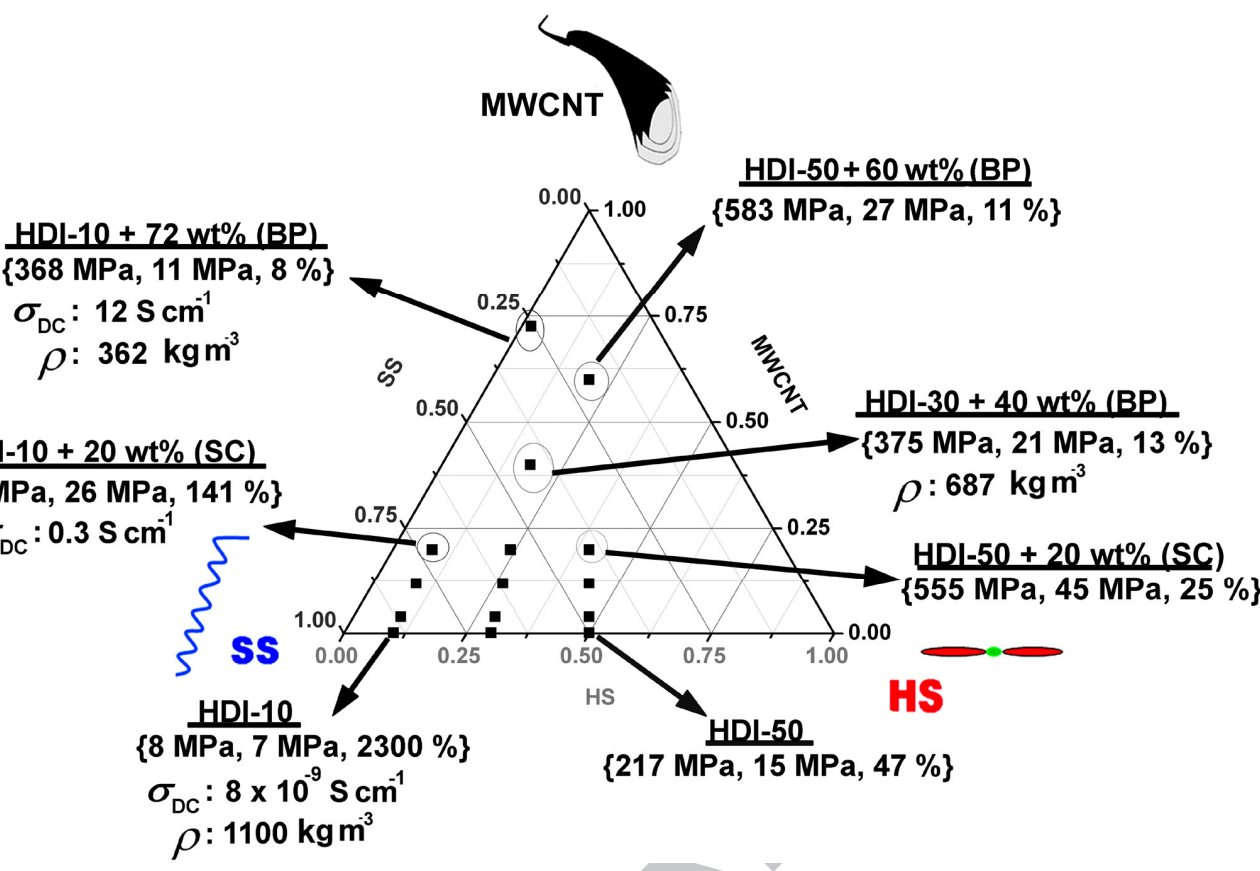

Fig.9

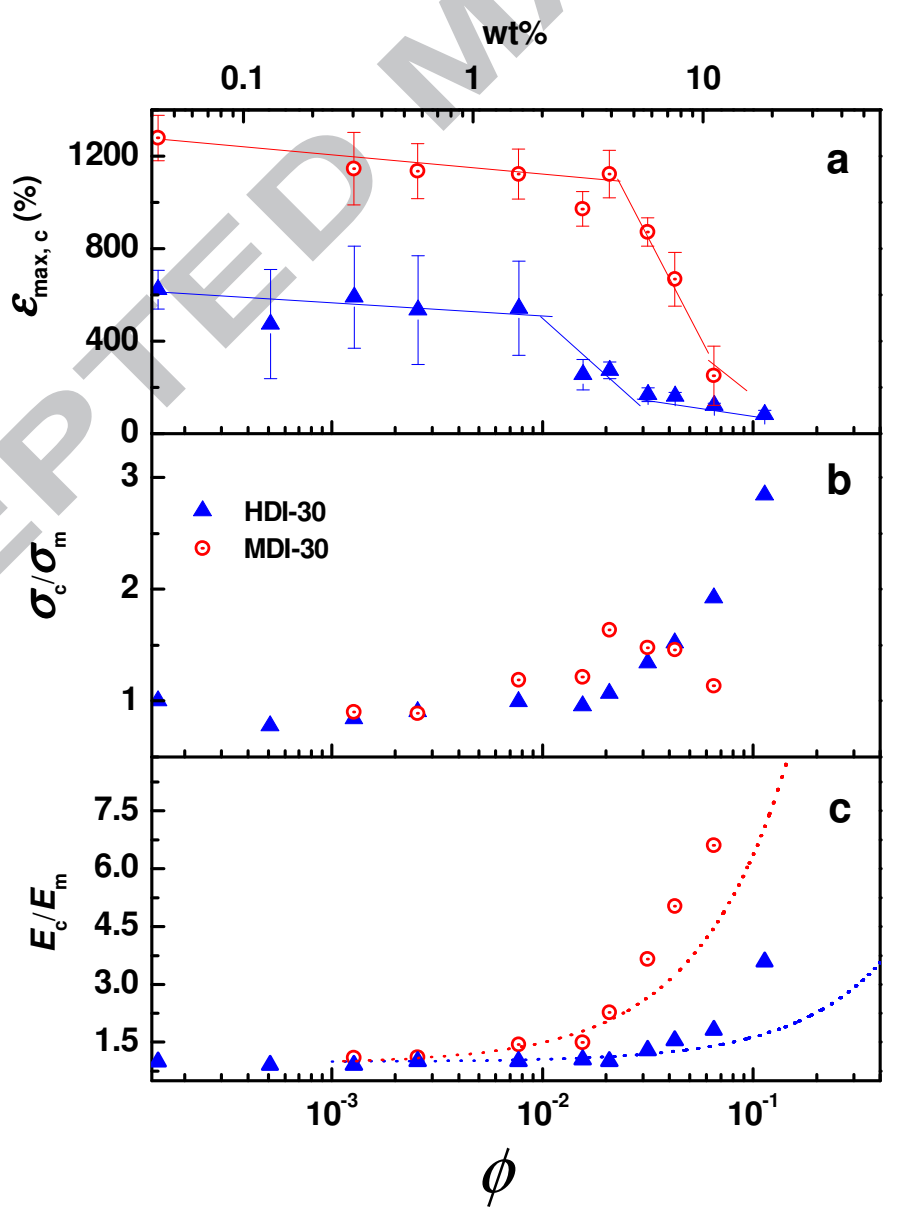

